Jurnal Agroteknologi, Vol. 6 No. 2, Februari $2016: 1$ - 8

\title{
ANALISIS SERAPAN TENAGA KERJA DAN PENDAPATAN PETANI KELAPA SAWIT DI KABUPATEN PELALAWAN
}

\author{
(Analysis of Labour Absorption and Income Palm Farmers in Pelalawan District)
}

\section{IRSYADI SIRADJUDDIN}

Program Studi Agroteknologi, Fakultas Pertanian dan Peternakan, Universitas Islam Negeri Sultan Syarif Kasim Riau

Email : irsyadi@uin-suska.ac.id HP : 08124280001

\begin{abstract}
This research aims to know (1) characteristics of farmers oil palm; (2) analysis of labour absorption; and (3) analysis of oil palm production; and (4) analysis of farmers income. The research was conducted in August 2015 until November 2015. Location of research in sub-districts of Bandar Seikijang, Langgam, Pangkalan Kuras, and Ukui in Pelalawan District. The method used interviews, questionnaires, and documentation. Sampling was done by purposive. The results showed (1) Characteristics of age of farmers are productive. While the characteristics of farmer education including secondary level (high school); (2) The most of labor absorption in sub-district Ukui $(4,04$ HOK / ha), followed by Bandar Seikijang (3,85 HOK / Ha), Pangkalan Kuras (3,80 HOK / ha), and Langgam (3,56 HOK /Ha); and (3) The highest productivity of oil palm in District Ukui (20,80 ton/ha), followed by Pangkalan Kuras (19,02 ton/ha), Bandar Seikijang (17,21 ton/ha), and Langgam $(15,44$ ton/ha). (4) The biggest income of farmers in District Ukui (Rp 23.750.347, - /ha), followed by Pangkalan Kuras (Rp 22.193.508, - /ha), Bandar Seikijang (19.100.916,- / ha), and Langgam (Rp 14.099.540, - / ha).
\end{abstract}

Keywords : Oil palm, farmer characteristics, labour absoprtion, oil palm production, farmers income

\section{PENDAHULUAN}

Salah satu komoditas perkebunan yang bisa diandalkan sebagai usaha yang menguntungkan adalahperkebunan kelapa sawit. Perkebunan kelapa sawit mempunyai peranan penting dalam peningkatan kesejahteraan rakyat, penyediaan tenaga kerja, dan dampak terhadap ekonomi wilayah. Kelapa sawit merupakan salah satu komoditas yang penting dan strategis di Kabupaten Pelalawan karena peranannya yang cukup besar dalam mendorong perekonomian rakyat. Kelapa sawit merupakan tanaman primadona masyarakat pedesaan di Pelalawan. Hal ini cukup beralasan karena kabupaten Pelalawan memang cocok dan potensial untuk pembangunan pertanian perkebunan. Menurut BPS (2014) luas perkebunan kelapa sawit yang diusahakan di kabupaten Pelalawan pada tahun 2013 seluas 118.262,02 ha dengan tingkat produksi sebesar 44.614.131,05 ton per tahun, maka pada saat ini Pelalawan merupakan salah satu kabupaten dengan kelapa sawit terluas di Indonesia.

Menurut Afifuddin
pembangunan subsektor kelapa sawit
merupakan penyedia lapangan kerja yang
cukup besar dan sebagai sumber pendapatan
petani. Kelapa sawit merupakan salah satu

komoditas yang memiliki andil besar dalam menghasilkan pendapatan asli daerah, produk domestik bruto, dan kesejahteraan masyarakat. Lebih lanjut Syahza (2011) menyatakan egiatan perkebunan kelapa sawit telah memberikan pengaruh eksternal yang bersifat positif atau bermanfaat bagi wilayah sekitarnya. Manfaat kegiatan perkebunan terhadap aspek sosial ekonomi antara lain adalah: 1) Peningkatan kesejahteraan masyarakat sekitar; 2) Memperluas lapangan kerja dan kesempatan berusaha; 3) Memberikan kontribusi terhadap pembangunan daerah. Menurut Nu'man (2009) tenaga kerja perkebunan kelapa sawit merupakan salah satu faktor produksi yang menyerap biaya cukup besar sehingga perlu upaya untuk meningkatkan efisiensi.

$\mathrm{Di}$ berbagai daerah di Indonesia, usaha perkebunan rakyat menjadi sumber utama pendapatan penduduk (Taryono dan Ekwarso, 2012). Pola usaha tani yang dilaksanakan para petani ini adalah bertujuan untuk mengatasi pemenuhan kebutuhan hidupnya, sehingga nilai ekonomi dari usaha tani yang ditekuni mempunyai peranan yang berarti untuk meningkatkan pendapatan (Darmawi, 2009). Taraf hidup yang baik merupakan tujuan utama bagi petani yang dalam hal ini sangat tergantung dari pendapatan yang diperoleh, akan tetapi pada 
kenyataannya sebagian dari mereka relatif masih berpenghasilan rendah sehingga berpengaruh pada kehidupan sehari-hari (Mursidah, 2009).

Berdasarkan gambaran diatas maka usulan kegiatan penelitian ini meneliti Analisis Serapan Tenaga Kerja dan Pendapatan Petani Kelapa Sawit di Kabupaten Pelalawan.

Adapun tujuan penelitian ini adalah (1) Untuk mengetahui karakteristik petani kelapa sawit; (2) Untuk mengetahui serapan tenaga kerja perkebunan rakyat kelapa sawit; (3) Untuk mengetahui produksi kelapa sawit; dan (4) Untuk mengetahui pendapatan usahatani perkebunan rakyat kelapa sawit.Adapun manfaat dari penelitian ini dapat mengetahui(1) karakteristik petani kelapa sawit dari segi umur dan pendidikan petani; (2) Serapan tenaga kerja perkebunan rakyat kelapa sawit. (3) produksi kelapa sawit (4) Pendapatan usahatani perkebunan rakyat kelapa sawit.

\section{BAHAN DAN METODE}

\section{Tempat dan Waktu}

Penelitian ini direncanakan dilaksanakan mulai Bulan Juli 2015 sampai dengan Oktober 2015. Tempat penelitian adalah sentra pengembangan kelapa sawit di Kabupaten Pelalawan. Kecamatan yang dipilih adalah Pangkalan Kuras, Ukui, Bandar Sei Kijang, dan Langgam. Berdasarkan data BPS (2014), empat kecamatan tersebut merupakan kecamatan dengan luas pengembangan perkebunan terbesar dan produksi tertinggi di Kabupaten Pelalawan.

Selain hal tersebut, alasan pemilihan keempat kecamatan tersebut, antara lain: 1) dalam rencana tata ruang wilayah (RTRW) Propinsi Riau, kabupaten tersebut merupakan bahagian dari pusat pengembangan perkebunan khususnya kelapa sawit (Dinas Perkebunan Propinsi Riau, 2011); 2) umur kelapa sawit pada keempat kecamatan tersebut pada usia produksi optimum yaitu umur 6 sampai 15 tahun; 3) banyak masyarakat melakukan usahatani kelapa sawit secara swadaya; dan 4) keempat kecamatan tersebut merupakan kecamatan dengan luas areal perkebunan terluas di Kabupaten Pelalawan.

\section{Metode Pengambilan Sampel}

Sampel diambil dari masyarakat di daerah kecamatan penelitian yang terpilih. Pengambilan sampel dilakukan secara purposive sampling sehingga masing-masing daerah terpilih terdapat sampel yang mewakili.
Metode ini digunakan dengan pertimbangan bahwa letak lokasi penelitian yang berpencaran dan karakteristik masyarakat sebagai objek penelitian yang beragam. Pengambilan sampel tersebut dilakukan sebagai berikut:

1. Memilih secara sengaja (purposive) kecamatan di Kabupaten Pelalawan. Kecamatan yang terpilih adalah Pangkalan Kuras, Ukui, Bandar Sei Kijang, dan Langgam. Kecamatan yang terpilih adalah kecamatan dengan luas produksi pengembangan terluas dan jumlah produksi terbanyak di Kabupaten Pelalawan.

2. Memilih petani secara acak sistematis (systematic random sampling) dalam kecamatan sampel. Pada setiap kecamatan sampel, dipilih 30 petani yang telah memenuhi kriteria tertentu, antara lain: 1) petani yang telah melakukan konversi lahan kebun kelapa sawit; 2) petani yang telah melakukan kegiatan usahatani kelapa sawit yang telah menghasilkan TBS; dan 3) petani yang umur tanaman kelapa sawitnya pada usia produksi optimum yaitu 5 sampai 15 tahun. Sehingga jumlah seluruh sampel adalah 120 petani.

Pengumpulan data primer dilakukan dengan menggunakan daftar pertanyaan yang telah disusun berdasarkan kebutuhan penelitian. Kuesioner berperan sebagai pedoman umum untuk mengingatkan peneliti agar tidak menympang dari tujuan penelitian.

Metode yang digunakan dalam memperoleh data di lapangan adalah:

1. Wawancara, yaitu dilakukan dengan bertatap muka langsung dengan responden untuk memperoleh informasi yang diinginkan.

2. Kuisioner, yaitu sejumlah pertanyaan tertulis diajukan ke responden.

3. Dokumentasi, yaitu dilakukan untuk memperoleh data tertulis, baik berupa laporan-laporan, foto-foto maupun laporan-laporan terdahulu, dan peta lokasi pengembangan kelapa sawit.

Jenis dan sumber data yang digunakan dalam penelitian ini adalah:

1. Data primer diperoleh dari petani melalui pengamatan langsung di lapangan dan wawancara langsung dengan menggunakan daftar pertanyaan / kuesioner. Penentuan kecamatan dilakukan secara sengaja, sedangkan penentuan responden di kecamatan dilakukan secara acak sistematis.

2. Data sekunder diperoleh dari instansi pemerintah yang menangani komoditas 
perkebunan pada umumnya dan kelapa sawit pada khususnya (Dinas Perkebunan, Kantor Statistik, Kantor Kecamatan, Kantor Desa, dII), baik ditingkat pusat, daerah / propinsi, kabupaten, dan desa sampai unit pelaksana (unit manajemen lapangan, pelaksana lapangan, dan kelompok tani).

\section{Analisa Data}

\subsection{Karakteristik Petani}

Untuk analisis karakter petani digunakan kategori menurut Kurniawati, et al (2008) dan Syahza (2011) bahwa umur produktif 29 s.d. 58 tahun. Sedangkan tingkat pendidikan digunakan kategori tingkat pendidikan nasional.

\subsection{Serapan Tenaga Kerja}

Untuk analisis penyerapan tenaga kerja digunakan jumlah curahan hari kerja yang digunakan oleh para petani. Jumlahnya dihitung mulai dari proses pengolahan lahan sampai panen.

\subsection{Produksi Kelapa Sawit}

Untuk analisis produktivitas ditentukan dengan rumus :Produktivitas $=$ Jumlah Produksi (ton) / luas produksi (ha)

\subsection{Pendapatan Petani Kelapa Sawit}

Pendapatan petani dilihat dari analisis usahatani perkebunan kelapa sawait. Penentuan pendapatan petani dengan persamaan: $\pi=T R-T C$; Dimana $\pi$ adalah keuntungan; TR adalah total penerimaan; dan TC adalah total pengeluaran.

\section{HASIL DAN PEMBAHASAN}

\section{Karakteristik Petani Sampel}

Keragaan aspek karakteristik petani mencakup umur dan tingkat pendidikan. Aspek ini merupakan faktor internal yang dapat memberikan latar belakang terhadap berbagai keputusan usahatani dan adopsi teknologi yang diambil petani. Karakterisitik petani sebagai hasil wawancara di lokasi penelitian diuraikan sebagai berikut:

\section{Umur Petani}

Umur petani dihitung dari tahun kelahiran sampai saat diwawancarai. Menurut Kurniawati, et al. (2008) bahwa Umur mempunyai pengaruh yang besar terhadap kemampuan untuk menjalankan pekerjaannya memilih jenis pekerjaan yang dilakukan. Ratarata penduduk yang bekerja di perkebunan termasuk kategori usia produktif yaitu berkisar antara umur 29-43 tahun. Dengan tingkat umur yang termasuk produktif berarti mereka dapat bekerja secara optimal. Lebih lanjut Syahza (2011) menyatakan bahwa umur produktif adalah 29-58 tahun, dan kurang produktif pada umur lebih besar dari 58 tahun.

Tabel 1. Penggolongan Umur Petani Responden Pada Empat Kecamatan di Pelalawan

\begin{tabular}{llccccccccc}
\hline \multirow{2}{*}{ No } & \multirow{2}{*}{ Umur (thn) } & \multicolumn{2}{c}{ Bandar Seikijang } & \multicolumn{2}{c}{ Langgam } & \multicolumn{2}{c}{ Pangkalan Kuras } & \multicolumn{2}{c}{ Ukui } \\
\cline { 2 - 12 } & & Jml & $\%$ & Jml & $\%$ & Jml & $\%$ & Jml & $\%$ \\
\hline 1 & $<29$ & 4 & 11,4 & - & 0 & 6 & 17,1 & 2 & 5,7 \\
2 & $29-43$ & 23 & 65,7 & 14 & 40,0 & 13 & 37,1 & 11 & 31,4 \\
3 & $44-58$ & 7 & 20,0 & 20 & 57,1 & 10 & 28,6 & 19 & 54,3 \\
4 & $>58$ & 1 & 2,9 & 1 & 2,9 & 6 & 17,1 & 3 & 8,6 \\
\hline
\end{tabular}

Berdasarkan Tabel 1, petani kelapa sawit berumur 29 s.d. 43 tahun dan 43 s.d. 58 tahun lebih banyak dari petani yang berumur kurang dari 29 tahun dan lebih dari 58 tahun. Hal ini menunjukkan bahwa secara umum, umur pada semua lokasi studi tergolong pada kategori umur produktif. Menurut Darmawi (2009), produktivitas kerja petani pada kondisi usia rata-rata 44,11 tahun telah dapat mengelola usaha taninya dengan semestinya sehingga usaha tani (kelapa sawit dengan luas lahan rata-rata 1,75 ha) telah dapat menghasilkan nilai ekonomis berupa pendapatan bagi petani. Lebih lanjut Syahza (2011) menyatakan bahwa umur produktif secara fisik akan sangat membantu dan potensial untuk melakukan berbagai aktivitas perkebunan kelapa sawit yang dikelolanya. Hal ini juga didukung oleh Lesmana, et al. (2011) bahwa umur akan mempengaruhi kemampuan fisik bekerja dan cara berpikir responden. Umur yang lebih muda biasanya cenderung lebih agresif dan lebih dinamis dalam berusaha bila dibandingkan dengan umur yang lebih tua. Disamping itu, umur juga mempengaruhi kinerja responden dalammengelola usahataninya.

\section{Tingkat Pendidikan}

Tingkat pendidikan seorang petani, baik itu pendidikan formal maupun non formal berpengaruh terhadap peningkatan produksi usahataninya. Dengan tingkat pendidikan petani tersebut, menurut Wiharno (1999) akan memberikan kemudahan bagi petani dalam mengadopsi teknologi dan keterampilan manajemen dalam mengelola usahataninya. Tingkat pendidikan petani dapat dilihat pada Tabel 2. 
Tabel 2. Penggolongan Tingkat Pendidikan Petani Pada Empat Kecamatan di Pelalawan

\begin{tabular}{lcccccccc}
\hline Tingkat & \multicolumn{2}{c}{ Bandar Seikijang } & \multicolumn{2}{c}{ Langgam } & \multicolumn{2}{c}{ Pangkalan Kuras } & \multicolumn{2}{c}{ Ukui } \\
\cline { 2 - 9 } Pendidikan & Jml & $\%$ & Jml & $\%$ & Jml & $\%$ & Jml & $\%$ \\
\hline SD & 12 & 34,3 & 15 & 42,9 & 12 & 34,3 & 11 & 31,4 \\
SMP & 9 & 25,7 & 5 & 14,3 & 5 & 14,3 & 8 & 22,9 \\
SMA & 11 & 31,4 & 13 & 37,1 & 16 & 45,7 & 14 & 40,0 \\
SARJANA & 3 & 8,6 & 2 & 5,7 & 2 & 5,7 & 2 & 5,7 \\
\hline & 35 & & 35 & & 35 & & 35 & \\
\hline
\end{tabular}

Tingkat pendidikan petani di empat kecamatan di Pelalawan dapat dilihat pada Tabel 4.2. Hal ini ditunjukkan oleh data pendidikan responden pada empat kecamatan yaitu tingkat pendidikan SMA 39\%, SD 36\%, SMP 19\%, dan Sarjana 9\%. Dari kondisi tingkat pendidikan petani tersebut dapat disimpulkan bahwa tingkat pendidikan petani kelapa sawit di semua kecamatan adalah menengah dan rendah. Menurut Syahza (2011) bahwa tingkat pendidikan rendah yaitu petani yang tidak tamat SD atau hanya tamat SD.

Pendidikan petani yang rendah mempengaruhi petani dalam melakukan kegiatan usaha perkebunan kelapa sawitnya. Hal ini didukung Wiharno (1999) menyatakan bahwa tingkat pendidikan petani mempengaruhi petani dalam mengadopsi teknologi dan keterampilan manajemen usahatani dalam usahataninya. Lebih lanjut Mahmud (2008) menyatakan bahwa tingkat pendidikan, wawasan, dan ekonomi petani sangat mempengaruhi perkembangan usaha taninya. Hal ini juga disampaikan oleh Lesmana, et al. (2011) bahwa pendidikan responden juga merupakan sarana penunjang dalam melakukan usahatani, pada umumya tingkat pendidikan yang lebih tinggi juga akan mempengaruhi cara berpikir responden untuk memandang masa depan yang lebih baik dan dalam menyerap informasi di bidang pertanian untuk kemajuan usahatani

yang dilakukan oleh responden.

\section{Serapan Tenaga Kerja}

Dalam bidang perkebunan, tenaga kerja merupakan faktor produksi kedua setelah lahan. Penggunaan tenaga kerja dinyatakan dalam besaran curahan hari kerja, yaitu curahan hari kerja dari tenaga kerja efektif yang terpakai. Sumber tenaga kerja berasal dari dalam keluarga dan luar keluarga. Menurut Nu'man (2009) tenaga kerja perkebunan kelapa sawit merupakan salah satu faktor produksi yang menyerap biaya cukup besar sehingga perlu upaya untuk meningkatkan efisiensi.

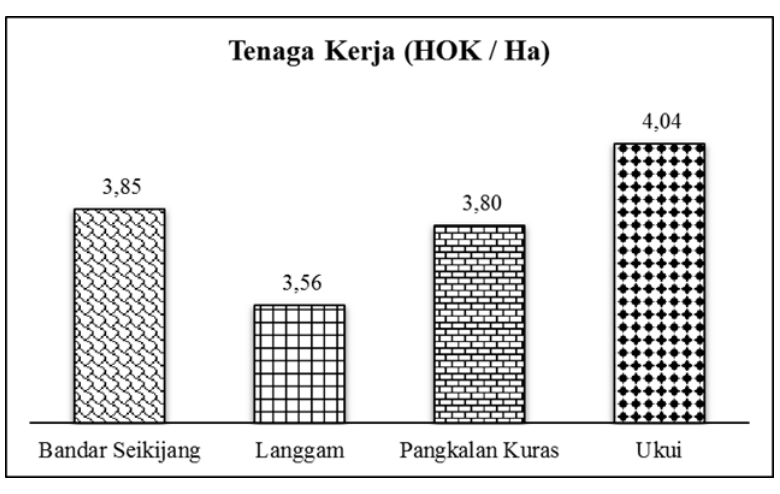

Gambar 1. Rata-Rata Hari Orang Kerja (HOK) per Ha Perkebunan Kelapa Sawit pada Empat Kecamatan di Kabupaten Pelalawan

Kebutuhan tenaga kerja pada kegiatan produksi tanaman perkebunan sangat bervariasi. Beberapa kegiatan yang dilakukan dan membutuhkan tenaga kerja diantaranya adalah pengolahan lahan, penanaman, pemupukan, pengendalian gulma, hama dan penyakit, dan panen. Jumlah hari orang kerja (HOK) untuk masing-masing komoditi per hektar luas lahan dapat dilihat pada Gambar 1.

Penggunaan tenaga kerja di Pelalawan terbanyak di kecamatan Ukui, Bandar Seikijang, Pangkalan Kuras, dan Langgam. Jumlah tenaga kerja per hektar pada masing-masing kecamatan tersebut adalah 4,04 $\mathrm{HOK} / \mathrm{Ha}, 3,85 \mathrm{HOK} / \mathrm{Ha}, 3,80$ $\mathrm{HOK} / \mathrm{Ha}$, dan 3,56 HOK/Ha. Banyaknya jumlah tenaga kerja di Ukui diduga mempengaruhi peningkatan produksi. Menurut Sutopo (2012) Tenaga kerja yang dibutuhkan mulai proses perawatan sampai panen sebanyak $4 \mathrm{HOK} / \mathrm{Ha}$ baik di lahan mineral maupun di lahan gambut. Menurut Syahza (2011) bahwa kebutuhan tenaga kerja terampil mengalami peningkatan sejalan dengan berubahnya orientasi sektor pertanian dari subsisten ke arah komersial. Kebutuhan tenaga kerja terampil dan berilmu semakin diperlukan untuk mampu bersaing. Tenaga kerja yang dibutuhkan tidak hanya menguasai ilmu pengetahuan dan teknologi tetapi juga mampu mengatasi berbagai masalah dalam pekerjaan dan memenangkan persaingan pasar global. 


\section{Produktivitas Petani Kelapa Sawit}

Menurut Saputra (2011), prospek kelapa sawit di Indonesia sangat besar, maka diperlukan upaya peningkatan produktivitas untuk meningkatkan produksi tanaman kelapa sawit. Salah satu upaya peningkatan produktivitas dapat dilakukan dengan cara adopsi teknologi pemupukan secara efisien dan efektif. Pemupukan merupakan faktor yang sangat penting untuk meningkatkan produktivitas dan kualitas produksi yang dihasilkan. Salah satu efek pemupukan yang sangat bermanfaat yaitu meningkatkan kesuburan tanah yang menyebabkan tingkat produktivitas tanaman menjadi relatif stabil. Selain adopsi teknologi pemupukan, adopsi intensitas teknologi pengendalian hama dan penyakit juga dapat meningkatkan daya tahan tanaman terhadap serangan penyakit dan pengaruh iklim yang tidak menguntungkan. Jika adopsi tinggi, maka pada pada akhirnya tercapai daya hasil (produktivitas) yang maksimal.

Gambar 2 menunjukkan bahwa produktivitas kelapa sawit tertinggi di Kecamatan Ukui, diikuti oleh Pangkalan Kuras, Bandar Seikijang, dan Langgam. Nilai masingmasing produktivitasnya adalah 20,80 ton/ha, 19,02 ton/ha, 17,21 ton/ha, dan 15,44 ton/ha.

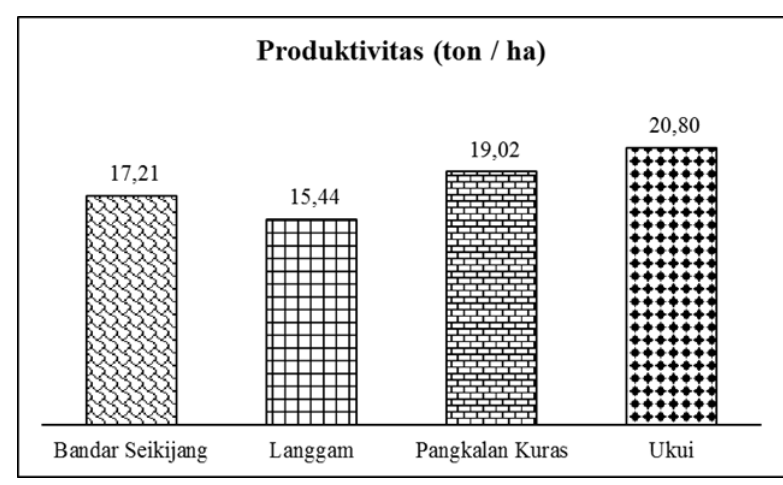

Gambar 2. Tingkat Produktivitas Petani Kelapa Sawit di Empat Kecamatan di Kabupaten Pelalawan.

Tingginya produktivitas di Kecamatan Ukui karena tingkat adopsi pemupukan urea, TSP, dan KCL yang sesuai anjuran dan jumlah tenaga kerja 4,04 HOK/ha yang sesuai standar. Menurut Arsyad (2012) pemupukan dapat mendukung produktivitas tanaman sawit, mengingat kelapa sawit tergolong tanaman yang konsumtif terhadap unsur hara. Menurut Rahayu, et al. (2008) pemberian unsur hara penting pada kelapa sawit maka pertumbuhan tanaman optimal dan produktivitas tanaman akan meningkat.

Menurut Mursidah

(2009)

Pengetahuan tentang jumlah sarana produksi yang tepat menyebabkan peningkatan biaya produksi yang ada dan pada akhirnya mempengaruhi pendapatan usahatani. Pendapatan maksimal, hanya dapat diperoleh jika produsen memilih tingkat produksi tertentu atau berproduksi pada tingkat optimal.

\section{Pendapatan Petani Kelapa Sawit}

Menurut Darmawi (2009) pola usaha tani kelapa sawit yang dilaksanakan petani bertujuan untuk mengatasi pemenuhan kebutuhan hidupnya, sehingga nilaiekonomi dari usaha tani yang ditekuni mempunyai peranan yang berarti untuk meningkatkan pendapatan. Pendapatan dari suatu usaha tani memerlukan perhitungan analisa terhadap penerimaan dan biaya-biaya yang dikeluarkan dalam usaha tani, sehingga dapat diketahui sejauh mana hasil yang dapat diperoleh. Menurut Taryono dan Ekwarso (2012) subsektor perkebunan rakyat ini merupakan lapangan kerja yang sangat luas bagi penduduk pedesaan. Di berbagai daerah di Indonesia, usaha perkebunan rakyat menjadi sumber utama pendapatan penduduk.

Gambar 3 menunjukkan bahwa pendapatan tertinggi di Kecamatan Ukui, diikuti oleh Pangkalan Kuras, Bandar Seikijang, dan Langgam. Nilai masing-masing pendapatan adalah $\mathrm{Rp} 23.750 .347,-/$ ha, Rp 22.193.508,/ha, Rp 19.100.0916/ha, dan Rp 14.099.540,/ha.

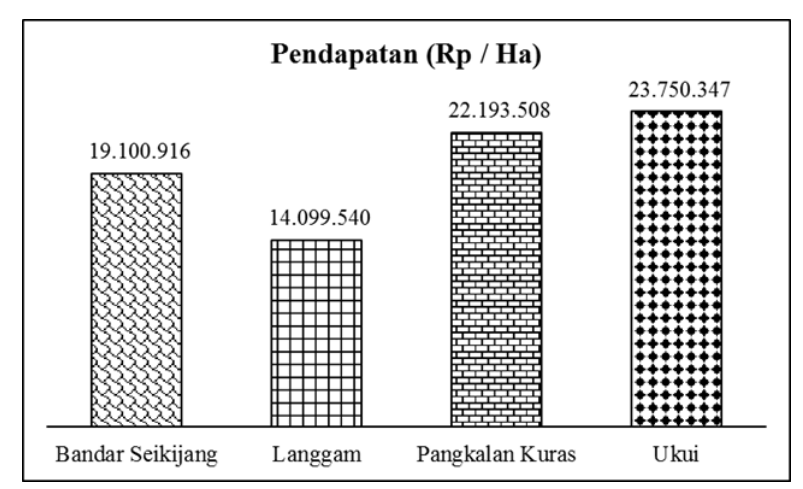

Gambar 3. Tingkat Pendapatan Petani Kelapa Sawit di Empat Kecamatan di Kabupaten Pelalawan.

Tingginya pendapatan dari usaha kelapa sawit menjadi aspek yang sangat menarik bagi petani untuk melakukan dan mengembangkan usahatani kelapa sawitnya. Menurut Hutasoit et al.(2015) aspek pendapatan merupakan salah satu aspek yang paling penting karena pendapatan merupakan penerimaan yang diterima petani dari usahatani yang dilakukan oleh petani. Pendapatan yang tinggi merupakan salah satu alasan petani melakukan usaha budidaya 
kelapa sawit. Sedangkan menurut Kausar (2011) pola pengelolaan kebun kelapa sawit swadaya merupakan pengusahaan atau pengelolaan kebun yang dilakukan oleh individu-individu dalama masyarakat secara swadaya dengan dana sendiri dan usaha mandiri. Dalam pola ini memegang peranan penting sebagai sumber pendapatan untuk menopang hidup keluarga walaupun pada kenyataannya produktifitas tanaman kelapa sawit yang diusahakan secara mandiri masih rendah dibandingkan dengan produktifitas dari kebun petani plasma maupun kebun inti.

\section{KESIMPULAN DAN SARAN}

\section{Kesimpulan}

Kesimpulan penelitian sebagai berikut:

1. Karakteristik umur petani termasuk kategori umur produktif. Sedangkan karakteristik pendidikan petani termasuk tingkat menengah (SMA).

2. Pendapatan kelapa sawit tertinggi di Kecamatan Ukui (Rp 23.750.347,-/ha), diikuti oleh Pangkalan Kuras (Rp 22.193.508,-/ha), Bandar Seikijang (19.100.0916/ha), dan Langgam (Rp 14.099.540,- /ha).

\section{Saran}

1. Bagi petani, adopsi teknologi pemupukan yang sesuai anjuran, tepat dosis, dan tepat waktu sehingga meningkatkan produksi dan produktivitas kelapa sawitnya.

2. Bagi pemerintah, agar dapat menyediakan pupuk dan obat-obatan tepat waktu dan mudah diperoleh oleh petani sehingga produksi dan produktivitas petani meningkat yang dapat meningkatkan pendapatan asli daerah.

\section{DAFTAR PUSTAKA}

Afifuddin, S., Kusuma, SI. 2007. Analisis Struktur Pasar CPO: Pengaruhnya terhadap pengembangan ekonomi wilayah Sumater Utara. Jurnal Perencanaan dan Pengembangan Wilayah. Vol. 2 No. 3. April 2007. Hal $124-136$.

Arsyad, AR. Heri Junaedi, dan Yulfita Farni. 2012. Pemupukan Kelapa Sawit Berdasarkan Potensi Produksi Untuk Meningkatkan Hasil Tandan Buah Segar (TBS) Pada Lahan Marginal Kumpeh. Jurnal Penelitian Universitas Jambi. Vol 14 No. 1. Januari - Juni 2012. Hal 2936.

BPS. 2014. Pelalawan dalam Angka. Riau.
Darmawi, Darlim. 2009. Aspek Ekonomi Pemeliharaan Sapi Program CSR (Corporate Social Responsibility) dalam Pola Usaha Tani Petani Kelapa Sawit di Kabupaten Tanjung Jabung Timur. Jurnal IImiah IImu-IImu Peternakan. Vol XII No. 2. Mei 2009. Hal 106-110.

Dinas Perkebunan Propinsi Riau. 2011. Laporan Tahunan. Dinas Perkebunan Propinsi Riau. Riau.

Kausar dan Komar Zaman. 2011. Analisis Hubungan Patron-Klien (Studi Kasus Hubungan Toke dan Petani Sawit Pola Swadaya Di Kecamatan Tambusai Utara Kabupaten Rokan Hulu. Indonesian Journal of Agricultural Economics (IJAE). Vo. 2 No. 2. Des 2011. Hal 183 200.

Kurniawati, F., Manumono, D., Panjang, S. 2008. Kajian Sosial Ekonomi Masyarakat Sekitar Perkebunan Kelapa Sawit PTPN III di Kab. Labuhan Batu Kec. Bilah Hulu Sumatera Utara. Buletin IImiah Instiper. Vol 15 No. 1. April 2008. Hal 6-14.

Lesmana, D., Rita Ratina, dan Jumriani. 2011. Hubungan Persepsi dan Faktor-Faktor Sosial Ekonomi Terhadap Keputusan Petani Mengembangkan Pola Kemitraan Petani Plasma Mandiri Kelapa Sawit (Elaeis guineensis Jacq.) di Kelurahan Bantuas Kec. Palaran Kota Samarinda. Jurnal Ekonomi Pertanian dan Pembangunan. Vol 8 No. 2 Tahun 2011. Hal 8-17.

Mahmud, Zainal. 2008. Modernisasi Usaha Tani Kelapa Rakyat. Jurnal Pengembangan Inovasi Pertanian. Vol I No. 4. Hal 274-287.

Mursidah. 2009. Optimalisasi Pendapatan Usahatani Kelapa Sawit.Jurnal EPP. Volume 6 No. 2 Tahun 2009. Hal 9 - 15.

Nu'man, M. 2009. Pengelolaan Tenaga Kerja Perkebunan Kelapa Sawit (Elaeis guineensis Jacq.) di Perkebunan PT Cipta Futura Plantation, Muara Enim, Sumatera Selatan. Skripsi. Fakultas Pertanian. Institut Pertanian Bogor. Bogor.

Rahayu, E., Hastudi, PB., dan Jusuf Banamtuan. 2008. Kajian Produktivitas Kelapa Sawit (Elaeis guineensis Jacq.) pada Lahan yang diaplikasikan Limbah Cair Pabrik Kelapa Sawit di PT. Sam. 1. Kab. Kampar, Riau. Buletin IImiah Instiper. Vol 15 No. 1. April 2008. Hal 24 $-47$. 
Saputra, Raja Ade. 2011. Evaluasi Pempupukan Pada Kelapa Sawit (Elaeis guineensis Jacq.) di Kebun Radang Seko Banjar Dalam, PT. Tunggal Perkasa Plantations, Indragiri Hulu. Riau. Skripsi. Departemen Agronomi dan Hortikultura. Fakultas Pertanian. Institut Pertanian Bogor.

Sutopo. 2012. Peranan Perkebunan Kelapa Sawit Terhadap Penyerapan Tenaga Kerja di Kab. Bengkalis. http://repository.unri.ac.id/xm/ui/bitstrea $\mathrm{m} /$ handle/123456789/2111/jurnal\%20sut opo.pdf. Diakses tanggal 12 September 2015.

Syahza, Almasdi. 2011. Percepatan Ekonomi Pedesaan Melalui Pembangunan Perkebunan Kelapa Sawit. Jurnal Ekonomi Pembangunan. Volume 12, Nomor 2, Desember 2011, hal 297-310.

Taryono dan Hendro Ekwarso. 2012. Analisis Ketenagakerjaan pada Wilayah Pedesaan di Kabupaten Kampar. Jurnal Sosial Ekonomi Pembangunan. Tahun III No. 7. Nov 2012 : 1 - 23.

Wiharno, H. 1999. Analisis Ekonomi Pengembangan Pertanian Tanaman Pangan di Kabupaten Dati II Sumedang. Tesis. Program Pascasarjana Universitas Hasanuddin. Makassar. 
Analisis Serapan Tenaga Kerja dan Pendapatan Petani Kelapa Sawit (Irsyadi Siradjuddin) 


\section{$\mathbf{J}$

PENGARUH PEMBERIAN PUPUK NT45 DAN PUPUK FOSFAT TERHADAP PERTUMBUHAN DAN HASIL TANAMAN KACANG TANAH

Effect of NT45 and Phosphate Fertilizer on Growth and Yield of Peanut

Nilla Kristina

RESPONS FISIOLOGI, PERTUMBUHAN, PRODUKSI DAN SERAPAN P BAWANG MERAH (Allium ascalonicum L.) TERHADAP PEMBERIAN TRICHOKOMPOS TANDAN KOSONG KELAPA SAWIT (TKKS) TERFORMULASI DAN PUPUK P DI LAHAN GAMBUT

Physiologcal Responses, Growth, Production and P Uptake by Shallots (Allium ascalonicum L.) Against Application of Trichokompos Oil Palm Empty Fruit Bunch (PEFB) Formulated and $P$ Fertilizer on Peatlands

Zaldi Arman, Nelvia, dan Armaini

PENINGKATAN EFISIENSI PUPUK FOSFAT MELALUI APLIKASI MIKORIZA PADA KEDELAI Increasing of Phosphor Efficiency by Mychorriza Application on Soybean

Indah Permanasari, Kartika Dewi, M. Irfan, dan Ahmad Taufiq Arminuddin

KANDUNGAN HARA MAKRO TANAH GAMBUT PADA PEMBERIAN KOMPOS Azolla pinata DENGAN DOSIS BERBEDA DAN PENGARUHNYA TERHADAP PERTUMBUHAN TANAMAN KANGKUNG (Ipomea reptans Poir)

Effect of Azolla pinata Compost with Different Doses for Macro Fertility of Peat Soil and It's Aplication in Plant Growth Kale (Ipomea reptans Poir)

Ervina Aryanti, Hadisa Novlina, dan Robbana Saragih

UJI PESTISIDA NABATI TERHADAP HAMA DAN PENYAKIT TANAMAN

Test of Biopesticide on The Crop Pest and Disease

Mokhamad Irfan 